\title{
Free Radical Scavenging Activity of Ethanolic Leaves Extract and Its Different Solvent Fractions of Piper betle $L$. In Vitro
}

\author{
Chandra Risdian ${ }^{1, *}$, Wahyu Widowati ${ }^{2}$, Tjandrawati Mozef ${ }^{1}$, Teresa Liliana \\ Wargasetia $^{2}$, Khie Khiong ${ }^{2}$ \\ ${ }^{1}$ Research Center for Chemistry, Indonesian Institute of Sciences, \\ Jl. Cisitu-Sangkuriang, Bandung 40135, Indonesia \\ ${ }^{2}$ Faculty of Medicine, Maranatha Christian University, \\ Jl. Prof drg. Suria Sumantri No.65, Bandung 40164, Indonesia
}

\begin{abstract}
Various diseases including cancer and cardiovascular diseases are induced by free radicals via lipid peroxidation, protein peroxidation, DNA damage, and cellular degeneration in the cells. Piper betle L., commonly called betel, belongs to the Piperaceae family. It originated from South and South East Asia, and has been used as a traditional medicine by people there due to its medicinal properties. In the present study, free radical scavenging activity of ethanolic leaves extract of Piper betle L. together with its different solvent fractions (hexane, ethyl acetate, butanol, and water) were evaluated by DPPH free radical scavenging assay. The ethanolic extract and the ethyl acetate fraction had shown very significant DPPH (I,I-diphenyl-2-picryl-hydrazyl) radical scavenging activity compared to the other fractions. In DPPH free radical scavenging assay, the $\mathrm{IC}_{50}$ value of the ethanolic extract and the ethyl acetate fraction were found to be $17.43 \mu \mathrm{g} / \mathrm{mL}$ and $11.53 \mu \mathrm{g} / \mathrm{mL}$, respectively. The free radical scavenging activity was assumed due to the total phenolic content. The total phenolic content was found to be highest in the ethanol extract (277.68 $\mu \mathrm{g} E G C G / \mathrm{mg})$ and the ethyl acetate fraction $(559.38 \mu \mathrm{g} \mathrm{EGCG} / \mathrm{mg})$. The results concluded that the ethanolic leaves extract of Piper betle L. and its ethyl acetate fraction have a considerably free radical scavenging activity.
\end{abstract}

Key words: Piper betle L., Piperaceae, free radical scavenging, DPPH

\section{INTRODUCTION}

Free radicals are reactive molecules having single unpaired electron which make them unstable thus can react or damage adjacent molecules. Externally sources of free radicals are cigarette smoke, environmental pollutants, radiation, and ultraviolet light. Free radicals called "Reactive Oxygen Species" (ROS) normally produced in the cells of aerobic organisms, especially in mitochondria. The ROS are also reported from products of xanthine oxidase, reaction involving iron or other transition metals, peroxisomes, and during inflammatory responses. However, ROS have roles in biological systems, such as killing infectious agents, and contributing in several signaling systems. In contrast, at high concentrations, various diseases including cancer and cardiovascular diseases are induced by ROS via lipid peroxidation, protein peroxidation, DNA damage, and cellular degeneration in the cells (Rahman, 2007; Bagchi and Puri, 1998). Some examples of ROS are superoxide radical anion $\left(\cdot \mathrm{O}_{2}\right)$, hydroxyl radicals $(\cdot \mathrm{OH})$, singlet oxygen $\left({ }^{1}\right.$ $\mathrm{O}_{2}$ ) and hydrogen peroxide $\left(\mathrm{H}_{2} \mathrm{O}_{2}\right)$ (Hsu et al., 2007). The unstable free radicals can be scavenged by substances called antioxidants. These may protect human body from deterioration caused by free radicals (Ara and Nur, 2009).

*Corresponding author e-mail: chan_ahsan@yahoo.com 
In the body ROS can react with antioxidants producing less-reactive species. There are a number of antioxidants in the body in the form of enzymes including superoxide dismutases (SODs), catalase, and glutathione peroxidases (GPxs) (Day, 2008).

However, these are not sufficient for balancing the production of ROS or free radicals from externally sources. The most effective way to increase antioxidant level in the body is by consuming nutritional antioxidants such as vitamin $\mathrm{C}$, vitamin $\mathrm{E}$ and many of these belonging to phenol family (Fusco et al., 2007).

Piper betle L., commonly called betel, belongs to the Piperaceae family. It originated from South and South East Asia. People in India, China, Taiwan, and South East Asia have used it as a traditional medicine due to its medicinal properties. The aqueous leaves extract of Piper betle L. has been reported to have antifungal activity (Ali et al., 2010), antibacterial activity (Nalina and Rahim, 2007), antioxidant activity (Dasgupta, 2004). An ethanolic leaves extract of Piper betle L. also has anti-inflammatory activity (Ganguly et al., 2007).

In the present study, free radical scavenging activity of ethanolic leaves extract of Piper betle L. together with its different solvent fractions (hexane, ethyl acetate, butanol, and water) were evaluated by DPPH (1,1-diphenyl-2picryl-hydrazyl) free radical scavenging assay. In addition, the total phenolic content of the ethanol extract and its different solvent fractions were also investigated.

\section{METHODS}

\section{Plant material}

Piper betle L. leaves were collected from plantation located in Bogor, west Java, Indonesia. The plants were identified by staff of herbarium, Department of Biology, School of Life Sciences and Technology, Bandung Institute of Technology, Bandung, West Java, Indonesia.

\section{Preparation of ethanolic leaves extract and fractionation of Piper betle $\mathbf{L}$}

The dried of leaves extract $(1 \mathrm{~kg})$ was grinded and immersed in $96 \%$ ethanol (Arumugam et al., 2006). After 72 hours the filtrate was collected, and the residue was immersed again by $96 \%$ ethanol for period of 72 hours. This treatment was repeated again until the filtrate became colorless. The combined filtrate was $26.6 \mathrm{~L}$, and then evaporated with rotary evaporator at $40^{\circ} \mathrm{C}$. The yield of ethanolic extract was $165.13 \mathrm{~g}$. The ethanolic extract was further partitioned using hexane and water (7:3). The aqueous layer was fractioned respectively with ethyl acetate (1:1) and butanol (1:1). The hexane, ethyl acetate, butanol, water fraction were collected and concentrated with vacuum rotary evaporator at $40^{\circ} \mathrm{C}$ and the yields are $1.4 \mathrm{~g}$, $33.117 \mathrm{~g}, 10.6 \mathrm{~g}$, and $35.9 \mathrm{~g}$, respectively.

\section{Assay of DPPH Free Radical Scavenging}

The free radical scavenging activity of the ethanolic leaves extract of Piper betle L., and its fractions (hexane, ethyl acetate, butanol, and water) were evaluated with DPPH (1,1-diphenyl2-picryl-hydrazyl) assay (Andarwulan et al., 2010). The amount of $50 \mu \mathrm{L}$ of the ethanol extract, its fractions and EGCG (Epigalochatechin Galat) as a standard in various concentrations were added with $200 \mu \mathrm{L}$ of 0.077 $\mathrm{mmol} / \mathrm{L}$ methanol solution of DPPH. The mixture was shaken and kept in the dark for $30 \mathrm{~min}$ at room temperature. The DPPH scavenging activity was determined by microplate reader at $517 \mathrm{~nm}$ wavelength. The free radical scavenging activity of each sample was expressed by the ratio of subtraction of the absorption of DPPH (\%), relative to the absorption $(100 \%)$ of DPPH solution in the absence of test sample (negative control).

$$
\text { scavenging } \%=\frac{A_{c}-A_{s}}{A_{c}} \times 100
$$

where $A_{s}$ and $A_{c}$ are absorbance at $517 \mathrm{~nm}$ of the mixture with samples and without sample respectively.

\section{Determination of total phenolic compounds}

The total phenolic compounds in the ethanolic leaves extract of Piper betle L., and its fractions (hexane, ethyl acetate, butanol, water) were determined with Folin-Ciocalteu reagent using EGCG as a standard (Chen and Yen, 2007).

\section{RESULTS}

Figure 1 shows DPPH radical scavenging activity of ethanolic leaves extract, hexane fraction, ethyl acetate fraction, butanol fraction and water fraction of Piper betle L., as well as 
EGCG as a standard. At the highest concentration $(125 \mu \mathrm{g} / \mathrm{ml})$, EGCG as a standard could scavenge DPPH 91.34\%. At the same concentration, the ethyl acetate fraction and the ethanol extract have scavenging activity very close to the standard, $87.49 \%$, and $86.09 \%$ respectively. The hexane fraction also has scavenging activity higher than $50 \%$ at this concentration $(70.27 \%)$. However, the lower DPPH scavenging activity was found for the water fraction, and the butanol fraction. These fractions have activity below $50 \%$, the former was $32.83 \%$, and the latter was $23.02 \%$.

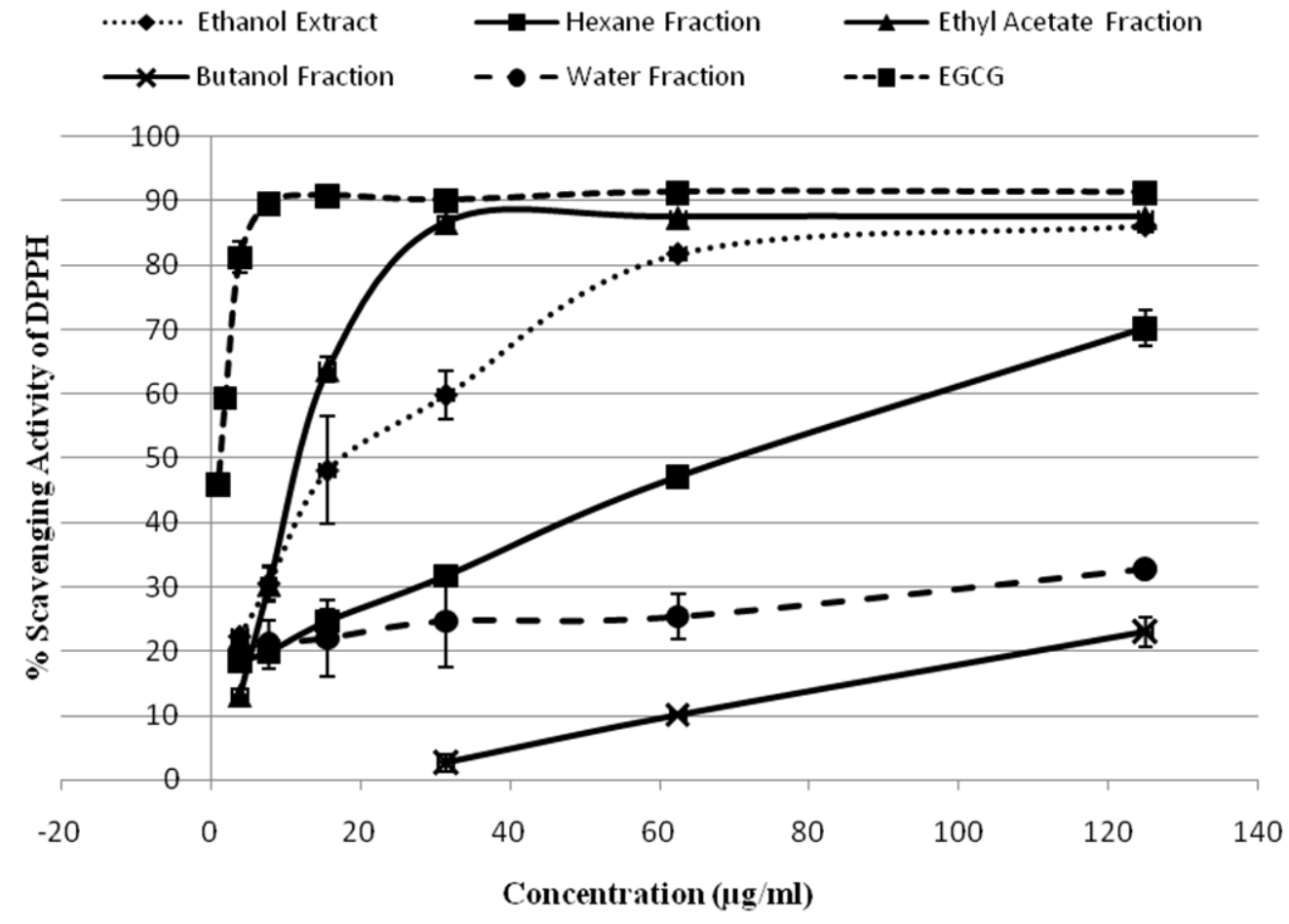

Figure I. DPPH radical scavenging activity of ethanolic leaves extract of Piper betle L., its solvent fractions, and EGCG as a standard. Data represents mean \pm standard deviation of triplicate experiments.

The comparison of $\mathrm{IC}_{50}$ values of $\mathrm{DPPH}$ scavenging activity among the ethanol extract, hexane fraction, ethyl acetate fraction, butanol fraction, water fraction, and EGCG as a standard is described in Table 1. It only needed $0.25 \mu \mathrm{g} / \mathrm{ml}$ EGCG to inhibit $50 \%$ DPPH, while it would need $3.48 \mu \mathrm{g} / \mathrm{ml}$ of ethanol extract, and $2.89 \mu \mathrm{g} / \mathrm{ml}$ of ethyl acetate to scavenge DPPH at such amount.
However, the higher result has been found in hexane fraction. In order to scavenge $50 \%$ of DPPH, it needed $14.97 \mu \mathrm{g} / \mathrm{ml}$ of hexane fraction or about four times much more than that of the ethanol extract. Even for butanol fraction as well as water fraction, the concentration $125 \mu \mathrm{g} / \mathrm{ml}$ could not scavenge $50 \%$ of DPPH yet. 
Table I. Comparison of IC 50 values of DPPH scavenging activity

\begin{tabular}{cc}
\hline Sample & $\mathbf{I C}_{\mathbf{5 0}}(\boldsymbol{\mu \mathbf { g } / \mathbf { m l } )}$ \\
\hline Ethanol extract & 3.48 \\
Hexane fraction & 14.97 \\
Ethyl acetate fraction & 2.89 \\
Butanol fraction & $(>25)$ \\
Water fraction & $(>25)$ \\
EGCG & 0.25 \\
\hline
\end{tabular}

The results of total phenolic compounds analysis in ethanolic leaves extract, hexane fraction, ethyl acetate fraction, butanol fraction, and water fraction of Piper betle L. was listed in Table 2. The total phenolic compounds were determined as the number equivalent to EGCG. The ethyl acetate fraction has the highest number of total phenolic compounds (568.19 $\mu \mathrm{g}$
EGCG/mg). Meanwhile, the ethanol extract and the hexane fraction have 269.97 and $215.58 \mu \mathrm{g}$ EGCG/mg respectively. These results were about a half less than the ethyl acetate fraction. The lowest number has been found in the butanol fraction (199.06 $\mu \mathrm{g}$ EGCG/mg) and the water fraction $(138.34 \mu \mathrm{g} / \mathrm{ml})$.

Table 2. Total phenolic compunds of ethanolic leaves extract of Piper betle L., and its solvent fractions

\begin{tabular}{cc}
\hline Sample & Total Phenolic Compunds \pm SD $(\boldsymbol{\mu g}$ EGCG/mg) \\
\hline Ethanol extract & $269.97 \pm 31.29$ \\
Hexane fraction & $215.58 \pm 20.50$ \\
Ethyl acetate fraction & $568.19 \pm 20.86$ \\
Butanol fraction & $199.06 \pm 5.79$ \\
Water fraction & $138.34 \pm 63.25$ \\
\hline
\end{tabular}

\section{DISCUSSION}

The damage in human body such as lipid peroxidation, protein peroxidation, DNA damage, and cellular degeneration in the cells (Rahman, 2007; Bagchi and Puri, 1998) caused by free radicals could be prevented by antioxidant agents (Ara and Nur, 2009). While there is interaction between antioxidant agent and DPPH free radical, an electron or hydrogen atom from antioxidant agent is transferred to DPPH to change it become in the neutral form (Dasgupta and De, 2004). From Figure 1, it could be seen that the ethyl acetate fraction from ethanolic leaves extract of Piper betle L. has the highest DPPH free radical scavenging activity of all fractions at $25 \mu \mathrm{g} / \mathrm{ml}$. The activity was very close to EGCG as a standard of antioxidant agent at the same amount of concentration. This described that there are a lot of antioxidant agents consist in the ethyl acetate fraction. Besides, the results explained that the enormous amount of antioxidant agents in Piper betle L., were belong to semi polar compounds.

Further investigation in DPPH scavenging activity was the $\mathrm{IC}_{50}$ value determination. This $\mathrm{IC}_{50}$ value means concentration of sample required to scavenge $50 \%$ free radical (Dasgupta and De, 2004). From the Table 1, the DPPH free radical scavenging activity of the ethanol extract and its fractions compared to EGCG as a standard were in the order ethyl acetate fraction > ethanol extract $>$ hexane fraction. Meanwhile, the butanol and water fraction could not be determined because these fractions have $\mathrm{IC}_{50}$ value more than $25 \mu \mathrm{g} / \mathrm{ml}$. These results support the previous results that the ethyl acetate fraction has the largest amount of antioxidant agents of all fractions.

Total phenolic compounds of the ethanol extract and its different solvents were listed in Table 2. The phenolic compounds are the main constituents of antioxidant agents in plants. These included quercetin, rutin, naringin, catechins, caffeic acid, gallic acid and chlorogenic acid 
(Chen and Yen, 2007). Total phenolic compounds of the samples in the equivalent number to EGCG were in order ethyl acetate fraction > ethanol extract > hexane fraction > butanol fraction $>$ water fraction. These results suggested that ethyl acetate fraction has remarkable DPPH free radical scavenging activity because of its phenolic compounds. The -OH groups in phenolic compounds were thought have a significant role in antioxidant activity (Arumugam et al., 2006).

\section{CONCLUSION}

In conclusion, the ethyl acetate fraction of ethanolic leaves extract of Piper betle L. has considerable DPPH free radical activity and this activity is mainly due to its phenolic compounds. These results also suggested that the ethyl acetate fraction of ethanolic leaves extract of Piper betle L. may be used for chemopreventive agent to protect the damage of body because of free radicals agents. Further study is needed to determine the bioactive compounds.

\section{ACKNOWLEDGMENT}

The authors gratefully acknowledge the financial support of Directorate General for Higher Education, Ministry of National of Republic Indonesia for research grant of Hibah Bersaing 2010.

\section{REFERENCES}

Andarwulan, N., Batari, R., Sandrasari, D.A., Bolling, B. and Wijaya, H., 2010, Flavonoid content and antioxidant activity of vegetables from Indonesia, Food Chem., I 2 I, I23 I-I 235.

Ali, I., Khan, F.G., Suri, K.A., Gupta, B.D., Satt,i N.K., Dutt, P., Afrin, F., Qazi, G.N. and Khan, I.A., 2010, In vitro antifungal activity of hydroxychavicol isolated from Piper betle L. Ann Clin Microbiol Antimicrob. 9: 7.
Ara, N. and Nur, H., 2009, In Vitro Antioxidant Activity of Methanolic Leaves and Flowers Extracts of Lippia Alba, Res. J. Medicine \& Med. Sci., 4(I), I07-I 10.

Arumugam, P., Ramamurthy, P., Santhiya, S.T. and Ramesh, A., 2006, Antioxidant activity measured in different solvent fractions obtained from Mentha spicata Linn.: An analysis by ABTS.+ decolorization assay, Asia Pac J Clin Nutr., II9-124.

Bagchi K,, and Puri S., 1998, Free radicals and antioxidants in health and disease. East. Mediterr. Health J., 4(2), 350-360.

Chen, H.Y, and Yen, G.C., 2007, Antioxidant activity and free radical-scavenging capacity of extracts from guava (Psidium guajava L.) leaves, Food Chem., I 01 (2), 686-694.

Dasgupta N, and De B. 2004. Antioxidant activity of Piper betle L. leaf extract in vitro, Food Chem., 88, 219-224.

Day BJ. 2008. Antioxidants as Potential Therapeutics for Lung Fibrosis, Antioxid Redox Signal, I O(2), 355-370.

Fusco, D., Colloca, G., Monaco,

M.R.L. and Cesari, M., 2007, Effects of antioxidant supplementation on the aging process, Clin Interv Aging, 2(3), 377-387.

Ganguly S,Mula S, Chattopadhyay S, and Chatterjee M. 2007. An ethanol extract of Piper betle Linn. mediates its antiinflammatory activity via downregulation of nitric oxide, J Pharm Pharmacol. 59(5), 7II-7I8.

Hsu CY, Chan YP, and Chang J., 2007. Antioxidant activity of extract from Polygonum cuspidatum. BiolRes. 40: I3-2I.

Nalina T, and Rahim, ZHA. 2007. The Crude Aqueous Extract of Piper betle L. and its Antibacterial Effect Towards Streptococcus mutans, Am. J. Biochem. \& Biotech. 3(1), 10-15.

Rahman, K., 2007, Studies on free radicals, antioxidants, and co-factors, Clin Interv Aging, 2(2), 219-236. 